\title{
Spatiotemporal Changes of Rainfall Erosivity in Loess Plateau, China
}

\author{
Mohamed A. M. Abd Elbasit, ${ }^{1,2}$ Jinbai Huang, ${ }^{3}$ CSP Ojha, ${ }^{4}$ \\ Hiroshi Yasuda, ${ }^{1}$ and Eltayeb O. Adam ${ }^{5}$ \\ ${ }^{1}$ Arid Land Research Center, Tottori University, 1390 Hamasaka, Tottori 680-0001, Japan \\ ${ }^{2}$ Desertification Research Institute, National Center for Research, Khartoum 11111, Sudan \\ ${ }^{3}$ College of Hydraulic and Architecture of North East Agricultural University, Harbin 150030, China \\ ${ }^{4}$ Department of Civil Engineering, Indian Institute of Technology, Roorkee 247667, India \\ ${ }^{5}$ Remote Sensing Authority, National center for Research, Khartoum 11111, Sudan
}

Correspondence should be addressed to Mohamed A. M. Abd Elbasit; m_abdelbasit@hotmail.com

Received 16 January 2013; Accepted 6 February 2013

Academic Editors: J. Artiola, L. A. Dawson, W. Ding, and W. R. Roy

Copyright ( 2013 Mohamed A. M. Abd Elbasit et al. This is an open access article distributed under the Creative Commons Attribution License, which permits unrestricted use, distribution, and reproduction in any medium, provided the original work is properly cited.

\begin{abstract}
The reason for the severity of soil erosion in Loess Plateau can be attributed to three nonanthropogenic factors: rainfall erosivity, slope gradient, and loess soil. The rainfall erosivity is controlled by the rainfall characteristics. Generally, rainfall characteristics change drastically in space and time. The rainfall erosivity has been investigated using the modified Fournier index (MFI), annual rainfall, and precipitation concentration index (PCI). The study showed a decrease in average MFI by $10 \%$. However, the difference between the MFI in 1960s and 1990s was found to decrease in a large area in Loess Plateau, whereas there was an increase in MFI at the high latitude. The maximum decrease in the rainfall erosivity was higher in the southeast than that in the north and west. The $P_{y}$ was found to have a trend similar to the MFI, which further indicates that the MFI follows, to a high extent, the annual rainfall trend. The PCI was found to have trend opposite to MFI and $P_{y}$. The PCI increased in the north and west and decreased toward the southeast. The average temporal difference in the PCI between the 1960s, and 1990s was two percent.
\end{abstract}

\section{Introduction}

Soil erosion in Loess Plateau, China is a major environmental problem that limiting the area development. The generated sediment is transported by the Yellow River and deposited to Yellow Sea causing various offsite ecological problems. The problem of soil erosion in Loess Plateau received more attention from the government at various levels [1], such as reforestation of hillslopes and check dams construction. The concentration of rainfall in three months, namely, June, July, and August, coupled with sparse land cover, highly erodible soil, and steep slopes in Loess Plateau made the area highly susceptible for soil erosion. The concentration of rainfall in certain period has a large impact on the magnitude of rainfall erosivity. The rainfall erosivity can be defined as the potential of rainfall to cause soil erosion. The rainfall erosivity is a function of rainfall characteristics and rainfall runoff erosivity [2]. The resulted runoff from a rainfall event is highly dependent on rainfall characteristics. Thus, the soil erosion can be linked directly with rainfall characteristics. The rainfall characteristics are highly controlled by the drop size distribution (DSD) [3]; however, data related to DSD are rarely available in arid and semiarid regions. In Loess Plateau, the daily rainfall is proportional to the annual rainfall, which indicates that higher annual rainfall means higher rainfall intensity and rainstorm runoff erosivity [2]. This fact makes the evaluation of rainfall erosivity based on rainfall data with relatively coarse time resolution highly reliable for large-scale erosion evaluation.

The rainfall erosivity has been widely evaluated by the Revised Universal Soil Loss Equation (RUSLE) using rainfall and runoff erosivity factor ( $R$-factor). The $R$-factor can be 


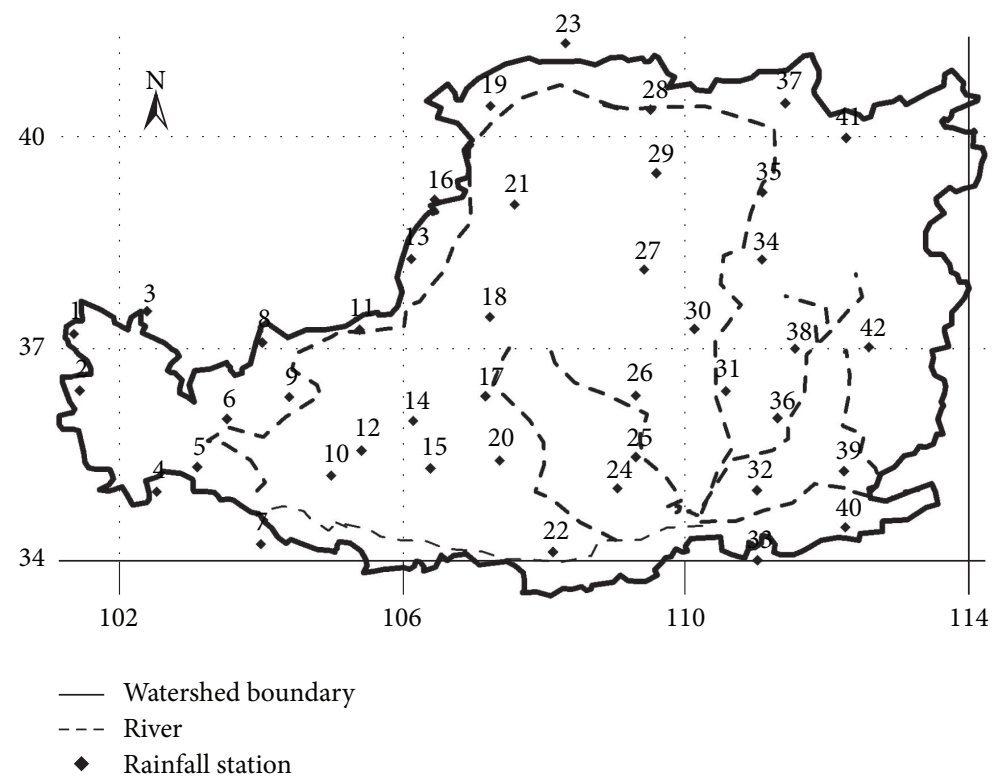

FIgUre 1: Chinese Loess Plateau and location of the rainfall stations considered in this study.

TABLE 1: Forty-year-, and ten-year-based average annual rainfall, the modified Fournier index, and precipitation concentration index for 42 rainfall stations located in Loess Plateau, China.

\begin{tabular}{|c|c|c|c|c|c|}
\hline Rainfall parameter & $\begin{array}{l}40 \text { years } \\
\text { average }^{\text {a }}\end{array}$ & $\begin{array}{c}\text { 1960s } \\
\text { average }^{\text {b }}\end{array}$ & $\begin{array}{c}\text { 1970s } \\
\text { average }^{\mathrm{b}}\end{array}$ & $\begin{array}{c}\text { 1980s } \\
\text { average }^{\mathrm{b}}\end{array}$ & $\begin{array}{c}\text { 1990s } \\
\text { average }^{\mathrm{b}}\end{array}$ \\
\hline$P_{y}$ & $417.54(22.20)$ & $448.92(24.11)$ & $413.98(22.31)$ & $420.67(23.88)$ & $386.54(19.47)$ \\
\hline MFI & $80.07(3.32)$ & 85.57 (3.79) & $80.37(3.54)$ & $78.92(3.72)$ & $75.40(2.80)$ \\
\hline PCI & $19.77(0.45)$ & $19.75(0.47)$ & $19.86(0.48)$ & $19.33(0.47)$ & $20.16(0.47)$ \\
\hline
\end{tabular}

The number between parentheses is the standard error; $P_{y}$ is annual rainfall (mm); MFI is modified Fournier index; PCI is precipitation concentration index.

${ }^{a, b}$ Number of data is 1680 , and 420 , respectively.

TABLE 2: Correlation coefficient between the rainfall parameters and geographical attributes $(n=42)$.

\begin{tabular}{lccc}
\hline $\begin{array}{l}\text { Rainfall } \\
\text { parameters }\end{array}$ & Longitude & Latitude & Altitude \\
\hline$P_{y}$ & $0.35(0.02)$ & $-0.68(<0.001)$ & $-0.07(\mathrm{~ns})$ \\
MFI & $0.56(<0.001)$ & $-0.45(0.002)$ & $-0.20(\mathrm{~ns})$ \\
PCI & $0.14(\mathrm{~ns})$ & $0.89(<0.001)$ & $-0.21(\mathrm{~ns})$ \\
\hline
\end{tabular}

The exponent between parentheses is the $P$ value; $P_{y}$ is annual rainfall (mm); MFI is modified Fournier index; PCI is precipitation concentration index.

defined as the product of total kinetic energy of storm times its 30-minute maximum rainfall intensity $\left(\mathrm{KE} \times I_{30}\right)$, which can be calculated as follows [4]:

$$
R \text {-factor }=\frac{1}{n} \sum_{i=1}^{n}\left[\sum_{k=1}^{m} \operatorname{KE}\left(I_{30}\right)_{k}\right]_{i},
$$

where $R$-factor is average rainfall and runoff erosivity (MJ mm ha ${ }^{-1} \mathrm{~h}^{-1}$ year $^{-1}$ ); KE is total kinetic energy of single storm $\left(\mathrm{MJ} \mathrm{ha}^{-1}\right) ; I_{30}$ is the maximum30-minute storm rainfall intensity $\left(\mathrm{mm} \mathrm{h}^{-1}\right) ; \mathrm{m}$ is the number of $k$ erosive storms at each $i$ year; and $n$ is the number of years used to obtain the average $R$-factor [4].

According to (1), rainfall data with half-hour time resolution is required to calculate the $R$-factor which is rarely available in arid and semiarid regions. Moreover, the calculation of $R$-factor required rainfall energy measurement which is usually derived from DSD data. Various relationships were suggested to relate the rainfall intensity with $\mathrm{KE}$ under different geographical locations and climate conditions [5-7]. Because of these data requirements, various indices were developed to evaluate the rainfall erosivity using daily, monthly, and annual rainfall data. Daily rainfall data at the rate greater than $9 \mathrm{~mm} \mathrm{day}^{-1}$ has been used to evaluate the rainfall erosivity in Loess Plateau [8]. On the other hand, researchers used the summation of half-month erosivity index $\left(M_{i}\right)$ method derived from daily rainfall rate greater than $12 \mathrm{~mm} \mathrm{day}^{-1}$ to evaluate the annual rainfall erosivity [9]. The $M_{i}$ is widely used in China to evaluate the erosivity rainfall $[9,10]$. The $M_{i}$ can be calculated as follows [10]:

$$
M_{i}=\alpha \sum_{j=1}^{k}\left(D_{j}\right)^{\beta}
$$




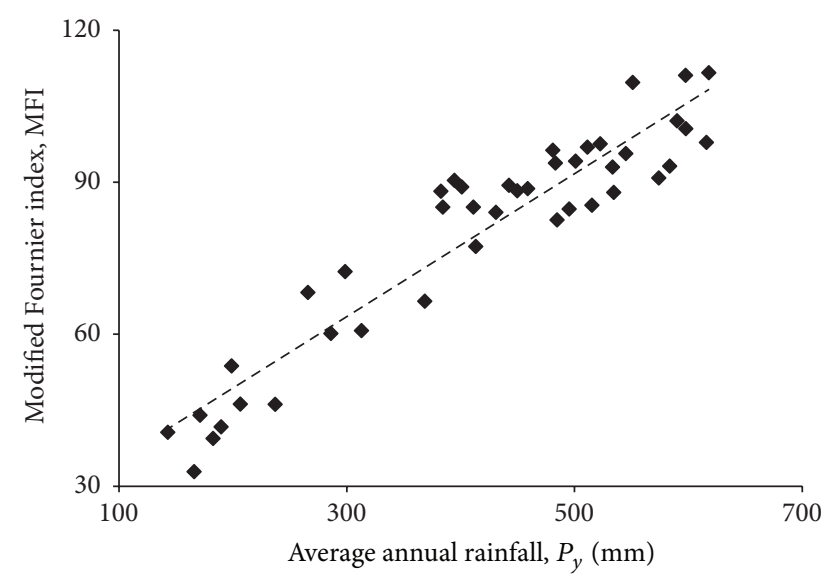

FigURE 2: Relationship between 40-year average annual rainfall $\left(P_{y}\right)$ and average erosivity modified Fournier index (MFI) using 42 rainfall station data located in Loess Plateau China.

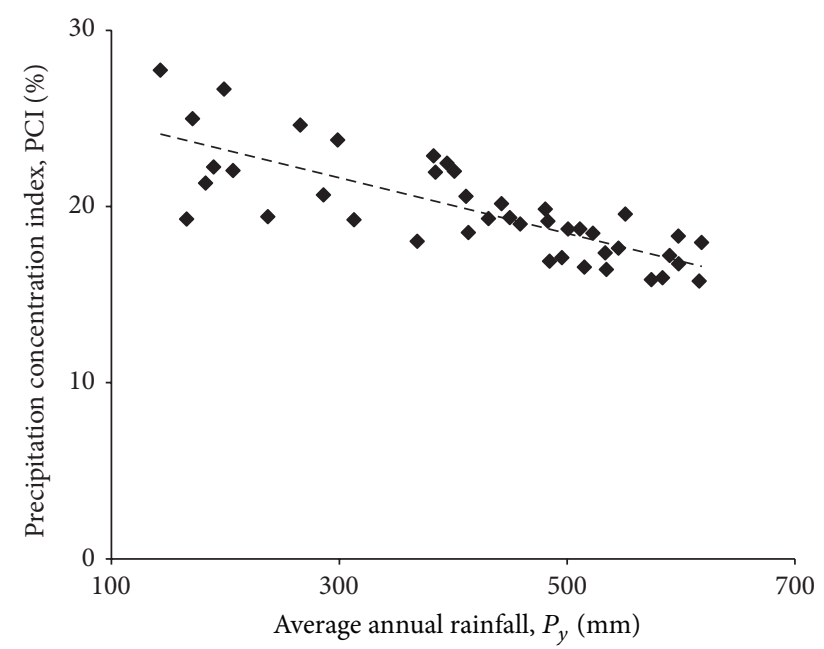

FIGURE 3: Relationship between 40-year-average annual rainfall $\left(P_{y}\right)$ and precipitation concentration index (PCI\%) using 42 rainfall station data located in Loess Plateau.

where $M_{i}$ is half-month rainfall erosivity (MJ mm $\mathrm{ha}^{-2} \mathrm{~h}^{-1}$ year $\left.^{-1}\right) ; D_{j}$ is effective rainfall for day $j$ in one half-month $(\mathrm{mm}) ; k$ is number of days in half month. The $D_{j}$ must be greater than or equal to $12 \mathrm{~mm}$ day $^{-1}$. The terms $\alpha$ and $\beta$ are empirical parameters calculated as follows:

$$
\begin{gathered}
\alpha=21.586 \beta^{-7.1891} \\
\beta=0.8363+\frac{18.144}{\bar{P}_{d 12}}+\frac{24.455}{\bar{P}_{y 12}},
\end{gathered}
$$

where $\bar{P}_{d 12}$ and $\bar{P}_{y 12}$ are the average daily rainfall larger than $12 \mathrm{~mm}$ and average annual rainfall for days with rainfall higher than $12 \mathrm{~mm}$ [10].

The rainfall erosivity can be also assessed using monthly and annual rainfall by employing the Fournier index 11 (Fournier, 1960). The index has been accepted widely in

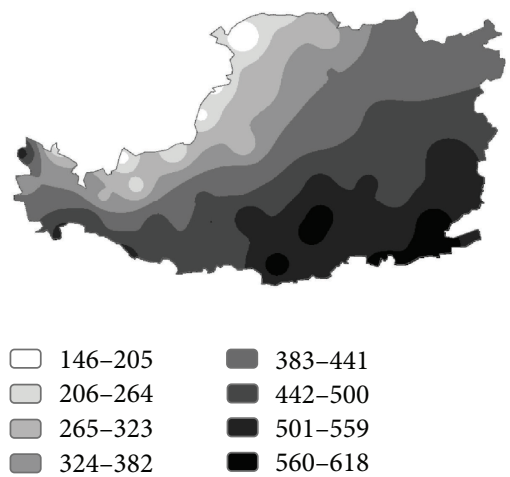

(a)
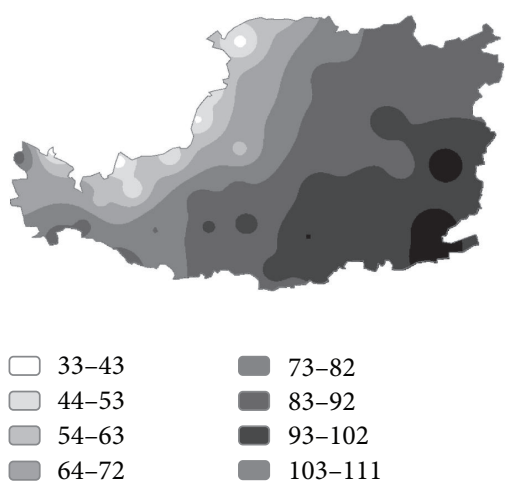

(b)
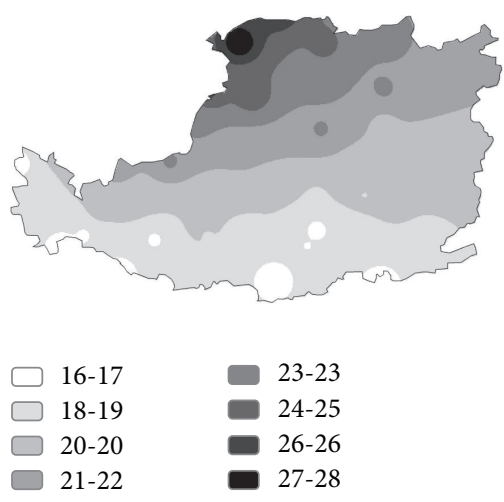

(c)

FIGURE 4: Spatial distribution of average annual rainfall (a), modified Fournier index (b), and precipitation concentration index (c) in the Chinese Loess Plateau determined from 42 stations for the period from 1960-2000.

different locations in the globe as a major erosivity indicator especially under rainfall data scarcity [11-14]. Moreover, recent development in satellite-borne rainfall data, such as Tropical Rainfall Measuring Mission (TRMM) by NASA, provided data with promising temporal and spatial resolution to be used for erosivity analysis in the near future by applying the Fournier index. The FI also has been used by several 

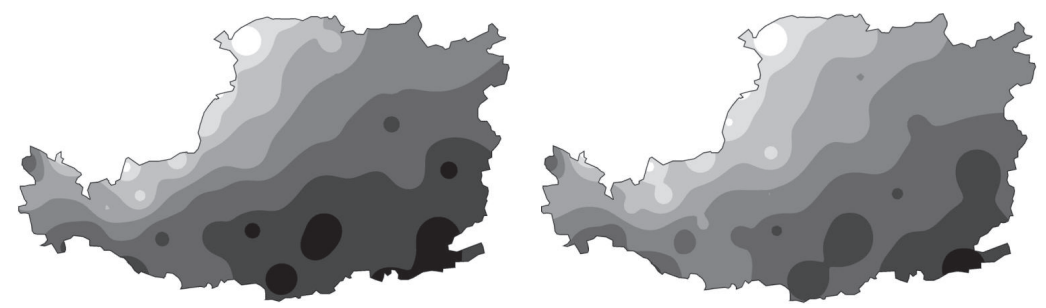

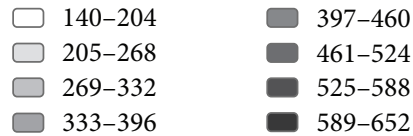

(a)
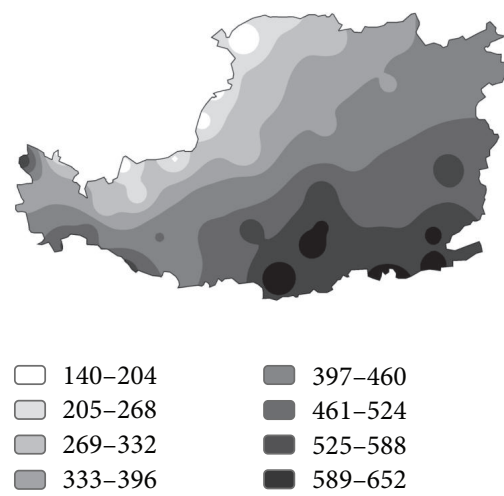

(c)

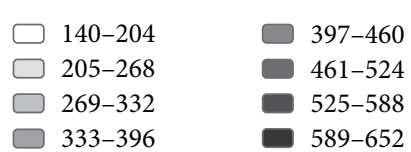

(b)

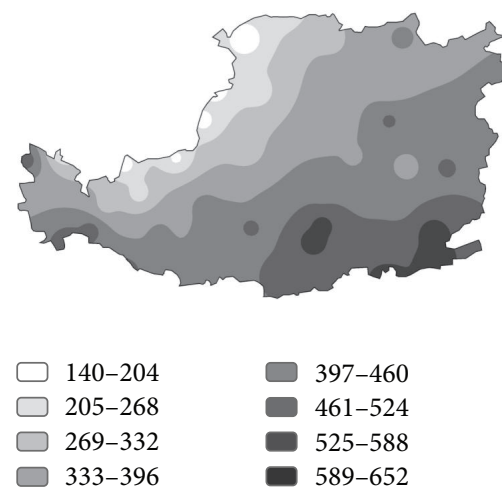

(d)

FIGURE 5: Spatiotemporal annual rainfall distribution in the Chinese Loess Plateau. (a) annual rainfall 1960s, (b) annual rainfall 1970s, (c) annual rainfall 1980s, and (d) annual rainfall 1990s.

researchers to determine the impact of different climate change scenarios on rainfall erosivity [15].

The aerial extend and topographic nature of the Chinese Loess Plateau is known by the existence of spatial variability in rainfall characteristics and erosivity. Moreover, Zhang et al. [15] reported that the presence of temporal variability in rainfall erosivity is due to climate change. The $M_{i}$ index has been used to evaluate the spatial and temporal variability of rainfall erosivity on the Chinese Loess Plateau which employs daily rainfall [10]. In this study, the spatiotemporal variability of rainfall erosivity for the period from 1960-2000 in the Chinese Loess Plateau will be assessed using monthly (FI, $M_{i}$, $\mathrm{EI}_{30}$ ) and annual rainfall (MFI) indices.

\section{Materials and Methods}

2.1. Study Area and Rainfall Data Set. Loess Plateau is located in the northeast of China covering an area equal to $640 \times$ $10^{3} \mathrm{~km}^{2}$. The study area covered approximately the whole area of the plateau which lies between latitudes $33.53^{\circ} \mathrm{N}$ and $41.18^{\circ} \mathrm{N}$, and longitudes $101.16^{\circ} \mathrm{E}$ and $114.23^{\circ} \mathrm{E}$ (Figure 1). The average elevation of the plateau is $1300 \mathrm{~m}$ above the mean sea level. The area is covered by loess soil highly susceptible for erosion by wind and water. The climate can be classified as a continental monsoon climate with annual rainfall range between 200 to $700 \mathrm{~mm}$ which increases from the northwest to the southeast. Rainfall in the Loess Plateau is concentrated in summer, particularly during June, July, August, and September [10]. The concentrated rainfall, low vegetation cover, high erodible soil, and steep slopes made Loess Plateau area with high potential for soil erosion.

Monthly rainfall data set were collected at 84 stations located at Loess Plateau for 40 years starting from 1960 to 2000. Data sets from stations that reported more than $10 \%$ missing values have been excluded from this study. Finally, 42 stations out of 84 were selected, and erosivity analysis has been done on these stations (Figure 1). The data were analyzed using Microsoft Spreadsheet Excel application. The data from the 42 stations were interpolated to generate equal size grids (approximately $1.1 \times 1.1 \mathrm{~km}$ ) using inverse distance weighted (IDW) method. The generated surfaces were analyzed using ArcGIS 9.3. The temporal variability was assessed using the average 10-year rainfall erosivity indices.

2.2. Calculations of Erosivity Indices. The monthly Fournier erosivity index (FI) was calculated using the following [16]:

$$
\mathrm{FI}=\frac{p_{i}^{2}}{P}
$$

where FI is Fournier Index; $p_{i}$ monthly rainfall depth in $i$ month; and $P$ is the annual rainfall. 

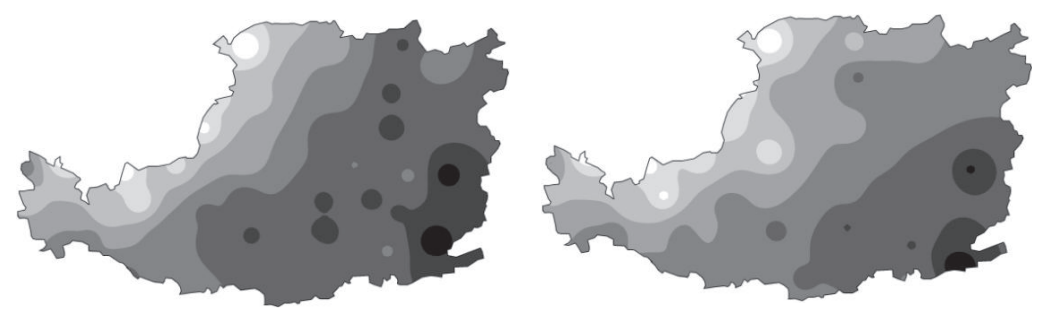

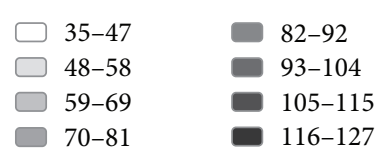

(a)
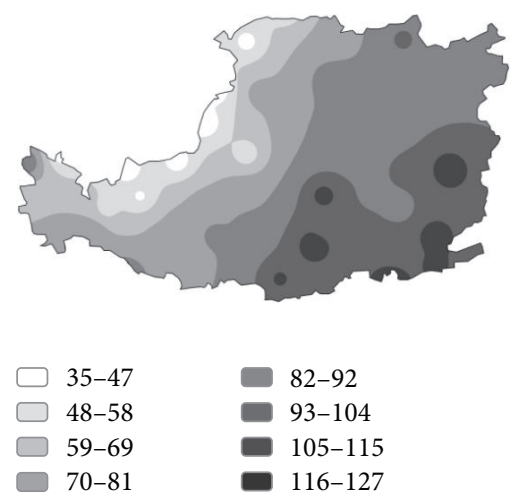

(c)

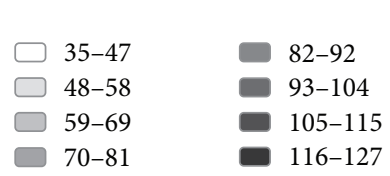

(b)

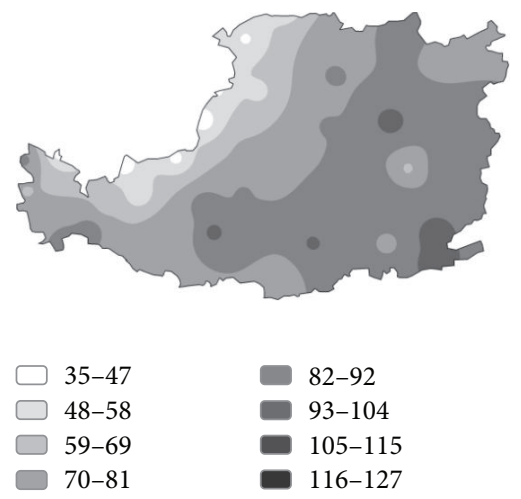

(d)

FIGURE 6: Spatiotemporal modified Fournier index distribution in the Chinese Loess Plateau. (a) Modified Fournier index rainfall, 1960s, (b) modified Fournier index rainfall, 1970s, (c) modified Fournier index, 1980s, and (d) modified Fournier index, 1990s.

The modified Fournier index (MFI) was calculated using the following [11]:

$$
\mathrm{MFI}=\frac{\sum_{i=1}^{12} p_{i}^{2}}{P}
$$

where MFI is the modified Fournier index. The MFI indicates the concentrated impact of rainwater on soil erosion. Higher MFI value means higher rainfall erosivity and vis-a-vis. Generally, the MFI range from 0 to 60 is defined as an indicator of very low erosivity, from 90 to 120 as moderate erosivity, from 120 to 160 as high erosivity, and greater than 160 as very high erosivity.

Another factor that affects the erosivity is the rainfall seasonality, which has been assessed usings precipitation concentration index (PCI), was calculated as follows [15]:

$$
\mathrm{PCI}=100 \sum_{i=1}^{12}\left(\frac{p_{i}^{2}}{P^{2}}\right)
$$

where PCI is the precipitation concentration index (\%) and the other variables were defined previously. The interpretation on the PCI was carried out as follows: uniform (PCI = $8.3-10 \%)$, moderately seasonal $(\mathrm{PCI}=10-15 \%)$, seasonal $(15-20 \%)$, highly seasonal $(\mathrm{PCI}=20-50 \%)$, and irregular $(\mathrm{PCI}=50-100 \%)$.

\section{Results and Discussion}

3.1. Temporal Pattern. Table 1 shows the average $P_{y}$, MFI, and PCI for 42 selected stations in the Loess Plateau. The average $P_{y}$ calculated from 40 -year data was $417.54 \mathrm{~mm}$. The temporal and spatial average variation in the $P_{y}$ was less than $6 \%$. The minimum $P_{y}$ in Loess Plateau was $143.01 \mathrm{~mm}$ found on the northwest where the maximum rainfall was $618.16 \mathrm{~mm}$ found on the southeast of the Loess Plateau. This result indicates that the maximum variation in the rainfall is more than $113 \%$ compared with $6 \%$ when compared with the average variation. This result emphasizes that the precipitation of Loess Plateau has a high variability in $P_{y}$ and it has subsequent impact on rainfall erosivity. The ten-year $P_{y}$ average showed general decrease in $P_{y}$. Comparing the $P_{y}$ in 1970s, 1980s, and 1990s with annual rainfall in 1960s, the $P_{y}$ showed decrease in $1970 \mathrm{~s}, 1980 \mathrm{~s}$, and $1990 \mathrm{~s}$ by $7.8 \%$, $6.3 \%$, and $13.9 \%$, respectively. Although there was a noticeable general decrease in $P_{y}$, the rainfall in 1980s showed little increase compared to $P_{y}$ in 1970s (Table 1). The MFI was found to follow the same decreasing trend compared to $1960 \mathrm{~s}$ average MFI (Table 1). Similar results on the deceasing of annual rainfall and half-month erosivity index $\left(M_{i}\right)$ by 10 and $15 \%$, respectively, have been reported [10]. The MFI was found to decrease by $6.1,7.8$, and $11.9 \%$ during 1970 s, 1980 s, and 1990s, respectively. Referring to these MFI results, the rainfall erosivity in Loess Plateau can be classified in the range 

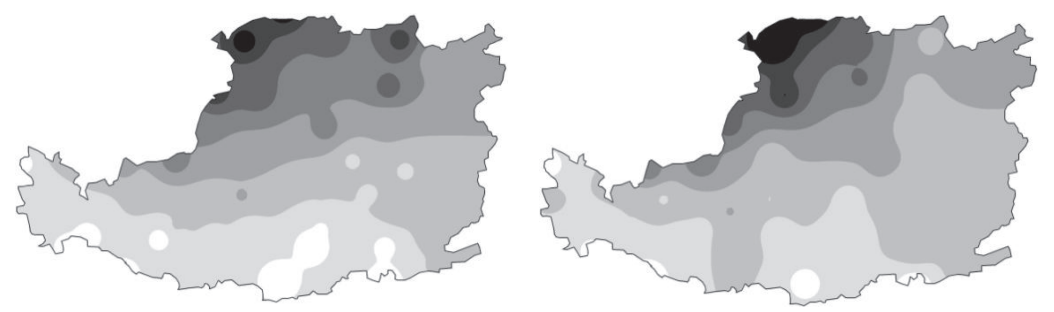
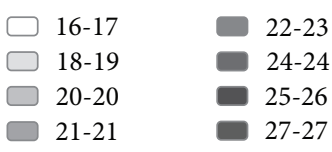

(a)
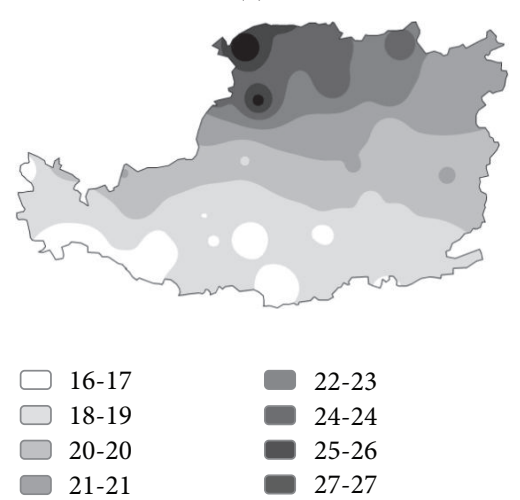

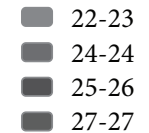

(c)

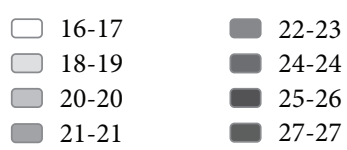

(b)

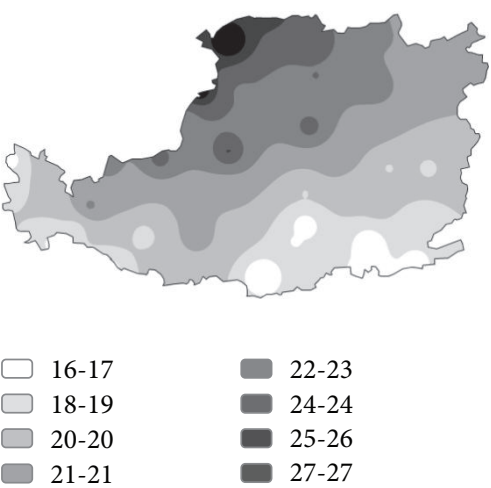

(d)

FIGURE 7: Spatiotemporal precipitation concentration index (\%) distribution in the chinese loess plateau. (a) Precipitation concentration index, 1960s, (b) precipitation concentration index, 1970s, (c) precipitation concentration index, 1980s, and (d) precipitation concentration index, 1990s.

between low and moderate erosivity [14]. The maximum and minimum MFI was 32.88 , and 111.57 , respectively. The PCI\% was approximately constant $(19.8 \%)$ which indicated that the rainfall in Loess Plateau follows a seasonal pattern without changes during the study period. The maximum and minimum PCI (\%) was 27.74 and $15.77 \%$, respectively, which is between moderate and high seasonality. The $P_{y}$ had significant positive correlation with the MFI and the correlation coefficient was $0.94(P<0.001)$, as shown in Figure 2. On the other hand, the $P_{y}$ had significant negative correlation with the $\mathrm{PCI} \%$ and the correlation coefficient was $-0.78(P<0.001)$ (Figure 3$)$. The MFI was found also correlated negatively with the PCI\% and the correlation coefficient was $-0.57(P<0.001)$.

3.2. Spatial Pattern. The $P_{y}$ increases from west to east directions, and decreases from the south to the north (Table 2). The $P_{y}$ was correlated positively with the longitude $(0.35$, $P=0.02)$ and negatively with the latitude $(-0.68, P<$ 0.001 ). The distribution of rainfall inside the Loess Plateau is controlled by the advance of the southwest equatorial air mass (tropical monsoon) against the polar frontal zone [17]. The MFI was correlated positively with the longitude $(0.56, P<$ $0.001)$ and negatively with the latitude $(-0.45, P=0.002)$. On the other hand, the PCI\% was correlated negatively with the latitude $(0.89, P<0.001)$. The impact of altitude on
$P_{y}, \mathrm{MFI}$, and PCI\% was found insignificant because of the change of altitude negatively with longitude and positively with latitude. This effect works in the opposite direction of the effect of the wet air mass flow (monsoon rainfall). Figure 4 shows the average $P_{y}$, MFI, and PCI\% spatial distribution. The spatial pattern showed high agreement with the statistical analysis discussed above. The rainfall parameters have been found to change with the latitude clearly and slightly with the longitude. The MFI was found in agreement with the $M_{i}$ distribution reported by [10]. The advantage of the MFI is that it was calculated using monthly rainfall data when compared with $M_{i}$ which is calculated for daily rainfall.

3.3. Erosivity Spatiotemporal Variability. In the previous two sections, the spatial and temporal changes of rainfall parameters $\left(P_{y}, \mathrm{MFI}\right.$, and PCI\%) were demonstrated. The complexity of rainfall variability in space and time suggested the employment of the mapping techniques in order to develop results readily applicable for soil erosion models. The spatial and temporal changes in $P_{y}$ are shown in Figure 5. The $P_{y}$ was found to decrease from northwest to the southeast with decreases in the areas covered by the darker colors and expansion of the area in light color in the north. This trend was also observed in the MFI (Figure 6). This indicated that there was a high association between the $P_{y}$ and MFI. On the other hand, the PCI\% was found to have contradicting trends 

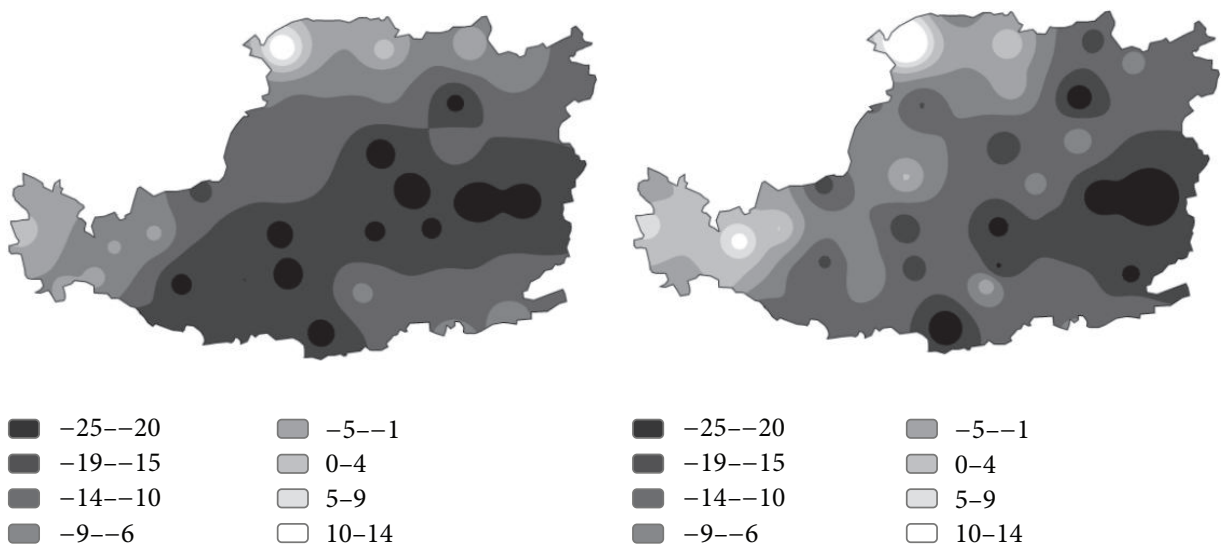

(a)

(b)

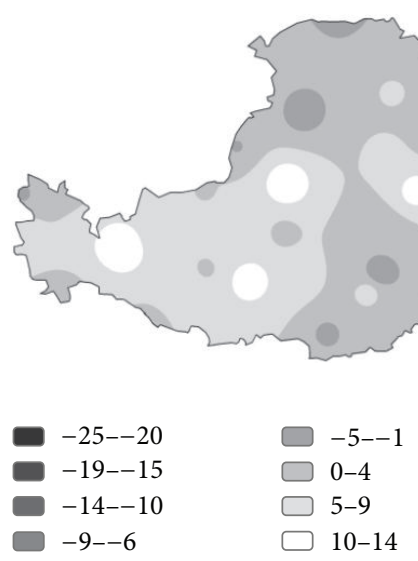

(c)

FIGURE 8: Spatial distribution of differences (\%) between 1960s and 1990s of the annual rainfall (a), the modified Fournier index (b), and the precipitation concentration index (c) in the Chinese Loess Plateau determined from 42 stations.

to that observed in the $P_{y}$ and MFI (Figure 7). This relationship can be confirmed by the negative correlation between the PCI from one side and the $P_{y}$, and MFI on the other side. The differences in the $P_{y}$ and MFI between 1960s and 1990s showed similar trend which increased in southeast and decreased toward the north and west (Figure 8). The PCI\% difference between 1960s and 1990s showed an increase in the southeast and a decrease toward the northeast (Figure 8).

\section{Conclusions}

The rainfall erosivity in the Chinese Loess Plateau showed a decrease of $10 \%$ between 1960s and 1990s. This decrease can be attributed to the decrease in rainfall in the region. The decrease in rainfall erosivity covered the majority of the Loess Plateau areas which suggested a subsequent decrease in sediment generation. However, the decrease in rainfall in the Loess Plateau may also negatively affect the vegetation cover development in the area which may expose more land to soil erosion. The general spatial trend of the rainfall erosivity and annual rainfall was found increasing in the southeast and decreasing towards the north and northwest. This trend did not change significantly during the study period. The rainfall seasonality had a trend contradicting with the annual rainfall and erosivity trend, which increases in the north and northwest and decreases toward the southeast.

\section{Acknowledgments}

This study was financially supported by the Japan Society for the Promotion of Science. The authors gratefully acknowledge the JSPS Core University Program and the Global COE Program of the Ministry of Education, Culture, Sports, Science, and Technology, Japan.

\section{References}

[1] L. D. Chen, J. Wang, B. J. Fu, and Y. Qiu, "Land-use change in a small catchment of northern Loess Plateau, China," Agriculture, Ecosystems and Environment, vol. 86, no. 2, pp. 163-172, 2001. 
[2] X. Jiongxin, "Precipitation-vegetation coupling and its influence on erosion on the Loess Plateau, China," Catena, vol. 64, no. 1, pp. 103-116, 2005.

[3] M. A. M. Abd Elbasit, H. Yasuda, A. Salmi, and H. Anyoji, "Characterization of rainfall generated by dripper-type rainfall simulator using piezoelectric transducers and its impact on splash soil erosion," Earth Surface Processes and Landforms, vol. 35, no. 4, pp. 466-475, 2010.

[4] K. G. Renard, G. R. Foster, G. A. Weesies, D. K. McCool, and D. C. Yoder, Predicting Soil Erosion by Water: A Guide To Conservation Planning with the Revised Universal Soil Loss Equation (RUSLE), issue 703 of Agriculture handbook, USDA, Washington, DC, USA, 1997.

[5] W. H. Wischmeier and D. D. Smith, "Rainfall energy its relationship to soil loss," Transaction of American Geophysics Union, vol. 39, pp. 285-291, 1958.

[6] N. W. Hudson, The influence of rainfall on the mechanics of soil erosion with particular reference to northern Rhodesia [M.S. thesis], University of Cape Town, 1965.

[7] A. W. Jayawardena and R. B. Rezaur, "Drop size distribution and kinetic energy load of rainstorms in Hong Kong," Hydrological Processes, vol. 14, no. 6, pp. 1069-1082, 2000.

[8] B. J. Fu, W. W. Zhao, L. D. Chen et al., "Assessment of soil erosion at large watershed scale using RUSLE and GIS: a case study in the Loess Plateau of China," Land Degradation and Development, vol. 16, no. 1, pp. 73-85, 2005.

[9] W. B. Zhang, Y. Xie, and B. Y. Liu, "Rainfall erosivity estimation using daily rainfall amounts," Scientia Goegraphica Sinica, vol. 22, pp. 705-711, 2002 (Chinese).

[10] Z. Xin, X. Yu, Q. Li, and X. X. Lu, "Spatiotemporal variation in rainfall erosivity on the Chinese Loess Plateau during the period 1956-2008," Regional Environmental Change, vol. 11, no. 1, pp. 149-159, 2011.

[11] H. M. Arnoldus, "An approximation of the rainfall factor in the universal soil loss equation," in Assessment of Erosion, M. de Boodt and D. Gabriels, Eds., pp. 127-132, John Wiley and Sons, Chichsester, UK, 1980.

[12] K. Oduro-Afriyie, "Rainfall erosivity map for Ghana," Geoderma, vol. 74, no. 1-2, pp. 161-166, 1996.

[13] C. Munka, G. Cruz, and R. M. Caffera, "Long term variation in rainfall erosivity in Uruguay: a preliminary fournier approach," Geo Journal, vol. 70, no. 4, pp. 257-262, 2007.

[14] N. A. Elagib, "Changing rainfall, seasonality and erosivity in the hyper-arid zone of Sudan," Land Degradation Development, vol. 22, no. 6, pp. 505-512, 2010.

[15] G. H. Zhang, M. A. Nearing, and B. Y. Liu, "Potential effects of climate change on rainfall erosivity in the Yellow River basin of China," Transactions of the American Society of Agricultural Engineers, vol. 48, no. 2, pp. 511-517, 2005.

[16] H. Fournier, Climat et erosion, Presses Universitaires de France, Paris, France, 1960.

[17] A. Kurashima and Y. Hiranuma, "Synoptic and climatological study on the upper moist tongue extending from southeast Asia to east Asia," in Water Balance of Monsoon Asia, M. M. Yoshino, Ed., pp. 152-169, University of Tokyo Press, Tokyo, Japan, 1971. 

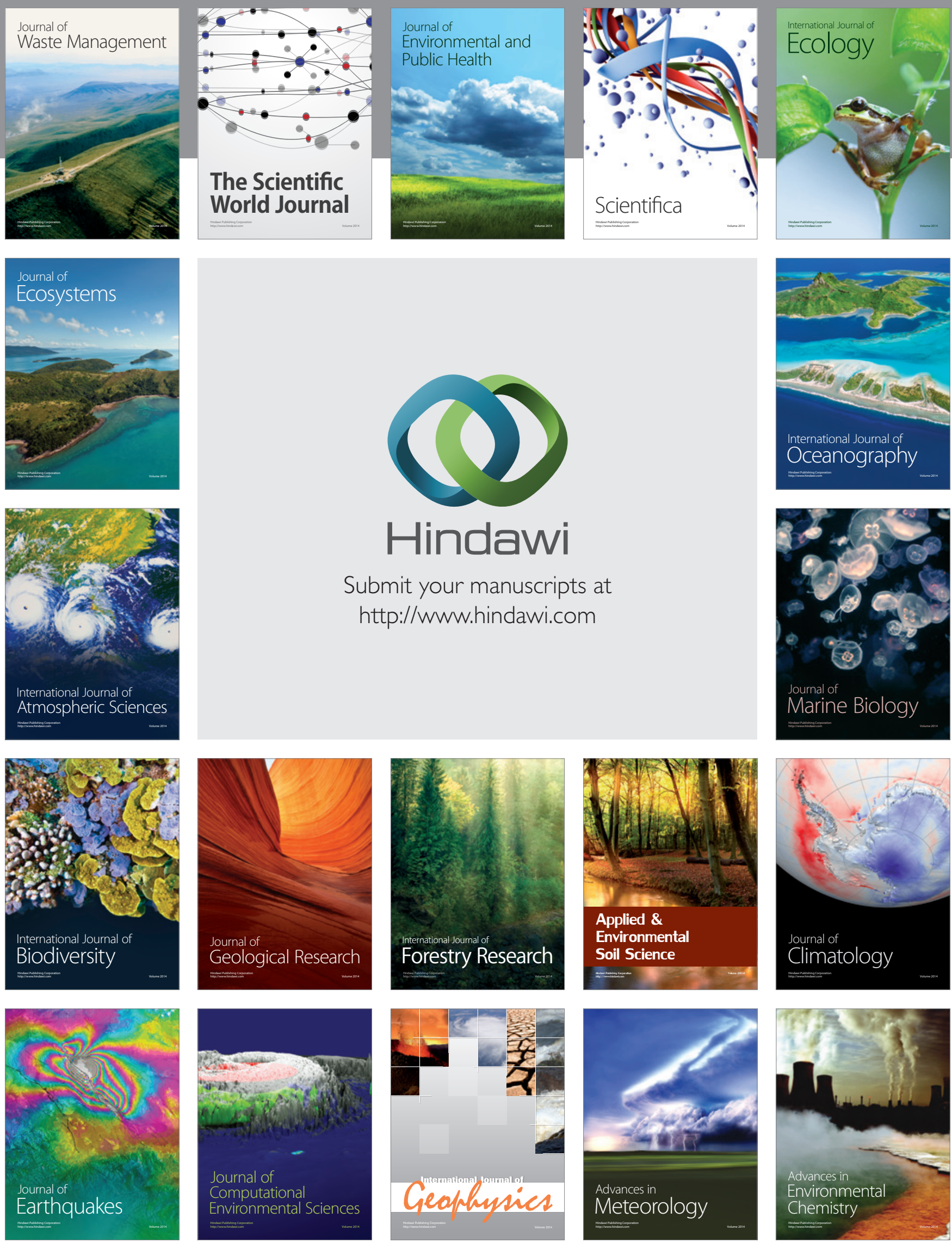